\title{
Safety Assessment of Nuclear Power Plants for Liquefaction Consequences
}

\author{
Tamás János Katona, ${ }^{1}$ Zoltán Bán, ${ }^{2}$ Erzsébet Gyơri, ${ }^{3}$ László Tóth, ${ }^{3}$ and András Mahler ${ }^{2}$ \\ ${ }^{1}$ University of Pécs, Boszorkány Utca 2, Pécs 7624, Hungary \\ ${ }^{2}$ Budapest University of Technology and Economics, P.O. Box 91, Budapest 1521, Hungary \\ ${ }^{3}$ Seismological Observatory, MTA CSFK GGI, Meredek Utca 18, Budapest 1112, Hungary \\ Correspondence should be addressed to Tamás János Katona; bata01@t-online.hu
}

Received 31 October 2014; Revised 1 March 2015; Accepted 11 March 2015

Academic Editor: Francesco Di Maio

Copyright ( 2015 Tamás János Katona et al. This is an open access article distributed under the Creative Commons Attribution License, which permits unrestricted use, distribution, and reproduction in any medium, provided the original work is properly cited.

\begin{abstract}
In case of some nuclear power plants constructed at the soft soil sites, liquefaction should be analysed as beyond design basis hazard. The aim of the analysis is to define the postevent condition of the plant, definition of plant vulnerabilities, and identification of the necessary measures for accident management. In the paper, the methodology of the analysis of liquefaction effects for nuclear power plants is outlined. The procedure includes identification of the scope of the safety analysis and the acceptable limit cases for plant structures having different role from accident management point of view. Considerations are made for identification of dominating effects of liquefaction. The possibility of the decoupling of the analysis of liquefaction effects from the analysis of vibratory ground motion is discussed. It is shown in the paper that the practicable empirical methods for definition of liquefaction susceptibility provide rather controversial results. Selection of method for assessment of soil behaviour that affects the integrity of structures requires specific considerations. The case of nuclear power plant at Paks, Hungary, is used as an example for demonstration of practical importance of the presented results and considerations.
\end{abstract}

\section{Introduction}

Proper understanding and assessment of safety of nuclear power plants (NPPs) with respect to external hazards became very important after 11 March 2011. Experience of Niigataken Chuetsu-oki earthquake of 16 July 2007 , the $M_{w} \approx 5.8$ Mineral (Virginia) earthquake of 2011, and also the response of Japan nuclear power plants to the Great Tohoku earthquake demonstrated that the design practice ensures the safety of nuclear power plants with respect to the vibratory ground motion. However, secondary effects of earthquakes that have not been properly considered in the design can heavily damage the plants, as in the case of the Fukushima Dai-ichi plant, where the tsunami led to fatal consequences after the plant survived the beyond design base ground vibratory motions.

Soil liquefaction can also be one of those secondary effects of earthquakes that should be accounted for at soft soil sites. Usually the liquefaction is not considered as a design base hazard. If the soil at the site is susceptible to the liquefaction, soil improvement and appropriate foundation design have to be applied for excluding the potential hazard. However, at some NPP sites, soil liquefaction has to be considered as a beyond design basis event, especially if the safety factor to liquefaction is rather low in case of design base earthquake.

Paks NPP is the only nuclear power plant in Hungary providing more than $40 \%$ of domestic electricity production. Originally, the plant was not designed for earthquake since the site seismic hazard was underestimated and the former Soviet design requirements did not require specific design measures for this case. In the early nineties, the site seismic hazard has been reevaluated using comprehensive probabilistic seismic hazard assessment (PSHA) methodology [1]; new seismic design basis has been defined with peak ground acceleration $0.25 \mathrm{~g}$ for $10^{-4} / \mathrm{a}$ nonexceedance level. Extensive safety upgrading measures have been implemented to comply with new design basis requirements [2]. The Paks site soil conditions are shown in Table 1 . The groundwater level is about $8.5 \mathrm{~m}$ below grade and varies with the seasonal 
TABLE 1: Soil description.

\begin{tabular}{ll}
\hline Depth, $\mathrm{m}$ & Stratum \\
\hline $0-2$ & Fill, variable loose sand and silt and soft clay \\
\hline $2-8$ & $\begin{array}{l}\text { Quaternary (Holocene) fluvial-aeolian strata with lenses from floods, very fine silty sand; the average thickness of lenses } \\
1.0-1.5 \mathrm{~m}\end{array}$ \\
\hline $8-15$ & Quaternary fluvial sand and gravel: medium to dense silty sand becoming gravelly sand at depth \\
\hline $15-27$ & Quaternary fluvial gravel \\
\hline $27-53$ & $\begin{array}{l}\text { Pannonian, greenish grey to } 45 \mathrm{~m} \text { then becoming yellowish brown, weakly bedded, and very silty fine sand with bands of } \\
\text { sandy silt }\end{array}$ \\
\hline $53-57$ & $\begin{array}{l}\text { Pannonian, ochreous colored laminated and ripple-bedded micaceous sandy silt becoming very silty clay between } 55 \text { and } \\
56 \text { m }\end{array}$ \\
\hline $57-67$ & Pannonian, yellowish brown weakly bedded silty fine sand \\
\hline $67-86$ & Pannonian, ochreous colored alternating bands of laminated and ripple bedded silty fine sand, sandy silt, and very silty clay \\
$86-100$ & $\begin{array}{l}\text { Pannonian, yellowish brown laminated micaceous silty fine sand with some sandy silt, below } 94 \mathrm{~m} \text { cross bedded silty fine to } \\
\text { medium micaceous sand }\end{array}$ \\
\hline
\end{tabular}

variation of the Danube water level. Probabilistic liquefaction hazard analysis performed in the early nineties [3] provided annual probability for liquefaction less than $10^{-4} / \mathrm{a}$. Consequently, the liquefaction was not considered as a design basis hazard, since the $10^{-4} / \mathrm{a}$ annual frequency is the criteria for accounting for an external hazard in the design basis.

After implementing the seismic upgrading measures, comprehensive seismic probabilistic safety assessment (seismic PSA) has also been performed. The seismic PSA demonstrates significant margins with respect to earthquake vibratory effect. The seismic PSA also accounted for the possibility of liquefaction via rather simplified way, practically assuming "cliff-edge effect" when the soil liquefies. The seismic PSA has shown that the liquefaction could be one of the essential contributors to the core damage. This finding motivated the investigations of the liquefaction hazard and safety consequences of the liquefaction. These efforts received high attention after Fukushima accident. Recently the liquefaction hazard as well as the plant response to liquefaction is extensively investigated for definition of safety margins and development of severe accident management procedures and measures. These activities are part of the national programme developed in the frame of focused safety assessment (stresstest) initiated by the European Union [4].

Conclusiveness of the beyond design base safety analysis for liquefaction depends on proper consideration of epistemic and aleatory uncertainties related to the uncertainties of assessment of ultimate behaviour of plant structures due to low probability complex effects. Therefore, the beyond design basis safety assessment for liquefaction is a complex procedure that integrates deterministic as well as probabilistic elements. The procedure consists of the following tasks:

(i) selection/development of the method for analysis of plant response to liquefaction that includes identification of accident scenarios and selection of methods for analysis of safety relevant systems, structures, and components, (ii) characterisation of liquefaction hazard that includes

(a) probabilistic seismic hazard assessment,

(b) investigation of the soil properties,

(c) selection of the appropriate methods for characterisation of liquefaction hazard,

(d) calculation of the liquefaction effects relevant for evaluation of plant response,

(iii) performing the safety analysis, identification of the plants vulnerabilities, and definition of accident mitigation measures.

Although the methods for assessment of the liquefaction hazard as well as the deterministic and probabilistic methodologies for evaluation of the liquefaction consequences have been widely studied, there is no experience or precedence for performing full scope safety analysis of an operating nuclear power plant for liquefaction.

In the paper, the issues of the selection of the method for beyond design basis safety analysis, practical problems of the selection of the method for assessment of the liquefaction hazard, and the calculation of relevant liquefaction effects are presented and discussed.

\section{Selection of Safety Analysis Methodology}

Recently several methodical documents have also been published on the development of severe accident management procedures, for example, [5]. According to this, plant vulnerabilities in the case of accidents beyond the design basis should be identified; knowledge on the behaviour of the plant during a beyond design basis accident should be obtained; the phenomena that may occur and their expected timing and severity should be identified. However, unified methodology does not exist for analysis of beyond design basis accidents caused by external events in combination with secondary effects, for example, earthquake and earthquake-induced soil 
TABLE 2: Relation between mechanism of structural displacement and earthquake parameters as well as parameters of the structure.

\begin{tabular}{|c|c|c|c|c|c|}
\hline \multirow[b]{2}{*}{ Increase in parameter } & \multicolumn{5}{|c|}{ Primary deformation mechanisms/mechanism of displacement } \\
\hline & $\begin{array}{c}\text { Localized } \\
\text { volumetric strains } \\
\text { due to partial } \\
\text { drainage }\end{array}$ & $\begin{array}{l}\text { Sedimentation } \\
\text { after liquefaction }\end{array}$ & $\begin{array}{l}\text { Consolidation due } \\
\text { to excess pore } \\
\text { pressure } \\
\text { dissipation }\end{array}$ & $\begin{array}{l}\text { Partial bearing } \\
\text { failure due to } \\
\text { strength loss in } \\
\text { foundation soil }\end{array}$ & $\begin{array}{c}\text { SSI-induced } \\
\text { building ratcheting } \\
\text { due to cyclic } \\
\text { foundation loading }\end{array}$ \\
\hline $\begin{array}{l}\text { Peak ground } \\
\text { acceleration (PGA) }\end{array}$ & $\uparrow \uparrow$ & $\uparrow \uparrow$ & $\uparrow \uparrow$ & $\uparrow \uparrow$ & $\uparrow \uparrow$ \\
\hline $\begin{array}{l}\text { Liquefiable layer rel. } \\
\text { density (Dr) }\end{array}$ & $\downarrow \downarrow$ & $\downarrow \downarrow$ & $\downarrow$ & $\downarrow \downarrow$ & $\uparrow \downarrow$ \\
\hline $\begin{array}{l}\text { Liquefiable layer } \\
\text { thickness }\end{array}$ & $\uparrow$ & $\uparrow$ & $\uparrow \uparrow$ & $\uparrow$ & $\uparrow \downarrow$ \\
\hline Foundation width & $\downarrow$ & $\uparrow \downarrow$ & $\uparrow$ & $\downarrow$ & $\downarrow \downarrow$ \\
\hline $\begin{array}{l}\text { Static shear stress ratio, } \\
\tau_{\text {static }} / \sigma_{v 0}^{\prime}\end{array}$ & $\downarrow$ & $\downarrow$ & $\downarrow$ & $\uparrow \downarrow$ & - \\
\hline $\begin{array}{l}\text { Height/width ratio of } \\
\text { structure }\end{array}$ & $\uparrow$ & $\uparrow$ & $\uparrow$ & - & $\uparrow \uparrow$ \\
\hline Building weight & $\uparrow \downarrow$ & $\uparrow \downarrow$ & $\uparrow \downarrow$ & $\uparrow \downarrow$ & $\uparrow \uparrow$ \\
\hline 3D drainage & $\uparrow \uparrow$ & $\downarrow$ & $\uparrow$ & $\downarrow$ & $\uparrow \downarrow$ \\
\hline
\end{tabular}

liquefaction. Contrary to this, essential progress has been achieved in the area of analysis for earthquake plus tsunami in the frame research programme of the International Atomic Energy Agency International Seismic Safety Centre [6].

The difficulties relate to the assessment of superposed effects of the ground vibratory motion and the liquefaction; that is, the liquefaction affects the plant twofold.

(i) Due to liquefaction, the site response becomes strongly nonlinear; that is, the liquefaction affects promptly the ground vibratory motion.

(ii) Liquefaction causes soil settlement, lateral spread, and so forth that can damage the plant structures.

These consequences of liquefaction are caused by several mechanisms of soil deformations that depend on the soil conditions, earthquake parameters, and parameters of the structure in a very complex manner. This is shown in Table 2 (see also [7]).

In Table 2, the arrows up indicate an increasing effect with increasing parameter value, while the arrows down indicate decreasing effect. Doubling of arrows corresponds to strong effect. Arrows in both directions indicate that the increasing of a parameter can cause controversial effects depending on conditions.

For the illustration of the plant response, let us take the simplified plant event-tree of the earthquake and subsequent liquefaction event shown in Figure 1. Loss of offsite power (LOSP) is assumed to be the initiating event caused by earthquake vibratory motion. The reactor shutdown system (denoted by $A$ ) shall ensure the subcriticality. The emergency power system $(B)$ and the emergency core cooling system $(C)$ are needed for avoiding the core damage. The success path after earthquake will be as follows: the reactor is subcritical; the emergency power supply and the emergency core cooling are ensured.
In case of Paks NPP, analysis of the site soil conditions and the features of critical plant structures resulted in the conclusion that the differential ground settlement due to liquefaction is the dominating effect that can damage the critical plant structures. The differential settlement can result in tilting and relative displacement between adjacent buildings that result in loss of integrity. The relative displacement between buildings and underground piping and cables can damage these communication lines. The latter affects mainly the power cables of the emergency power supply and the piping to the ultimate heat sink. It means the emergency power supply $(B)$ and the systems for heat removal $(C)$ could be affected by the soil settlement with time delay $\Delta t$ after strong motion starts. Once worked, the system A will continue to ensure the subcriticality, though the reactor might be tilted together with the reactor building due to liquefaction. Although it is not indicated in Figure 1, the differential settlement can also cause loss of integrity of the containment that should be also evaluated. Assuming the above scenario, the liquefaction can be considered as a separate load case subsequent to the vibratory motion.

The analysis of safety consequences of the above scenario can be performed by either deterministic or probabilistic method.

A probabilistic safety analysis of liquefaction (liquefaction PSA) requires the characterisation of the hazard, development of the plant event-trees and fault-trees, and knowledge of the fragility of systems, structures, and components (SSCs) relevant to safety. The fragility has to be defined as a function of engineering demand parameter that should be correlated with appropriate intensity measure characterising the earthquake hazard.

A performance-based earthquake engineering (PBEE) probabilistic framework for evaluation of the risk associated with liquefaction has been developed in [8-10]. In the PBEE, the earthquake is characterized by an intensity measure (IM), 


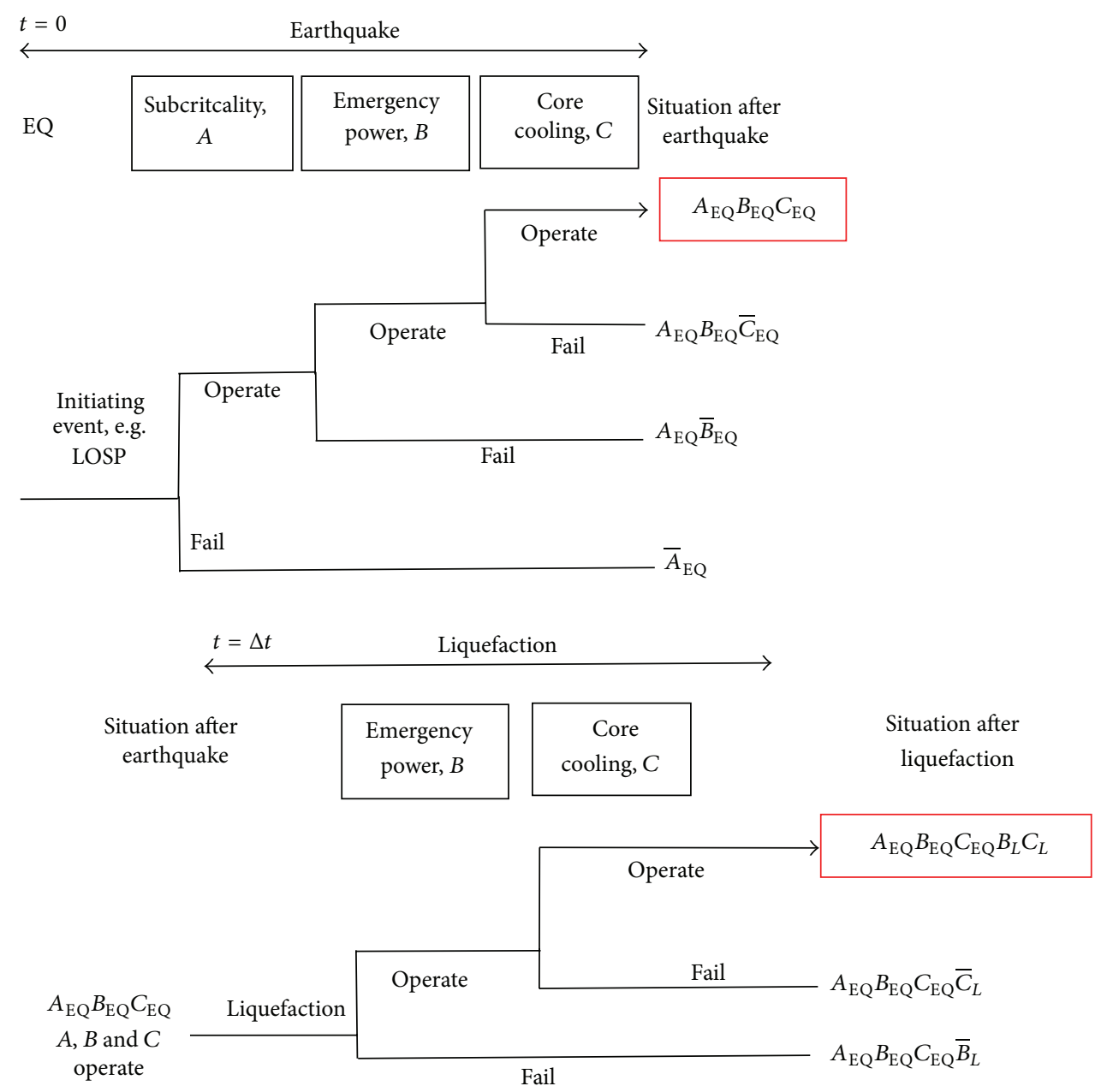

FIGURE 1: Simplified plant event-tree for earthquake and liquefaction.

for example, peak ground acceleration. An engineering demand parameter (EDP) has to be identified and the EDP should be correlated with the damage measures (DM) that are measures of physical effect of EDP. The risk associated with DM has to be expressed in some decision variables (DV) applicable for the risk characterization (some measure of loss). The mean annual rate of exceedance of a given DV level can be calculated if the annual rate of the IM and the conditional probabilities connecting the IM to EDP, the EDP to DM, and the DM to DV are known. The mean annual rate of exceedance of a given DV level, $\lambda_{\mathrm{DV}}$, can be expressed as

$$
\begin{aligned}
\lambda_{\mathrm{DV}}=\sum_{k=1}^{N_{\mathrm{DM}}} \sum_{j=1}^{N_{\mathrm{EDP}}} \sum_{i=1}^{N_{\mathrm{IM}}} P\left[\mathrm{DV} \mid \mathrm{DM}_{k}\right] \\
\cdot P\left[\mathrm{DM}_{k} \mid \mathrm{EDP}_{j}\right] P\left[\mathrm{EDP}_{j} \mid \mathrm{IM}_{i}\right] \Delta \lambda_{\mathrm{IM}_{i}},
\end{aligned}
$$

where functions of the type $P\left[a=a^{\prime} \mid b=b^{\prime}\right]$ describe the conditional probability of random variable, a given $b=$ $b^{\prime}$. The $\Delta \lambda_{\mathrm{IM}_{i}}$ is the $i$ th increment of mean annual rate of exceedance of IM. The $N_{\mathrm{DM}}, N_{\mathrm{EDP}}$, and $N_{\mathrm{IM}}$ are the numbers of increments corresponding to DM, EDP, and IM, respectively. In case of nuclear power plant safety analysis, the DV can be associated with loss of safety function if the measure of damage is exceeding the level of $\mathrm{DM}_{k}$. The aggregate mean annual frequency of exceeding a particular value of DV is then determined by summing up the contributions from all combinations of possible intensity measures, engineering demand parameters, and damage measures.

In spite of the comprehensiveness of the PBEE method, it is rather difficult to apply, since identification of parameters DM, EDP, and IM and definition of $\lambda_{\mathrm{IM}_{i}}$ are not trivial. The calculation of the aggregate mean annual frequency for DV requires the knowledge of multivariate distribution of intensity measures; hence the engineering demand parameters like soil settlement depend on the peak ground acceleration and on the magnitude of earthquake. The calculation can be simplified, if the marginal distributions of intensity measures are used which implies week correlation between the intensity measures. Further difficulties are related to the definition of the conditional probabilities (fragility functions) of the plant SSCs. The available information on the fragility of buildings, underground structures, and lifelines of nuclear power plants is rather scarce. Nevertheless, a liquefaction PSA has certain 
advantages, since it quantifies the core damage and early large release frequencies and identifies the plant vulnerabilities. However, the liquefaction PSA would not provide input information for the design of upgrading or mitigating measures.

Considering the abovementioned difficulties, a deterministic approach has been adopted for Paks NPP for the beyond design basis safety analysis of the liquefaction.

Deterministic safety analysis assesses the integrity and function of the plant SSCs while calculating the loads due to liquefaction, the stresses, and strains caused by these loads and comparing these to ultimate values. Thus, the procedure for analysis of plant response to the liquefaction as beyond design base event consists of the following steps.

(1) The first is probabilistic seismic hazard assessment that provides the peak ground acceleration and deaggregation matrices that are used in computations of magnitude for the liquefaction hazard analysis.

(2) The second is calculation of soil settlements due to the liquefaction.

(3) The third is identification of SSCs within the scope of liquefaction safety analysis. These are the SSCs needed for ensuring the heat removal from rector and spent fuel pool as well as the SSCs that are important for accident management. The identification of the SSCs has been done in the frame of Targeted Safety Review (see [4]). Thus, the SSCs within the scope of liquefaction safety analysis are as follows.

(a) SSCs have to be functional or preserve their integrity, as it is required for emergency heat removal (see $[4,5])$. In the case of Paks NPP that are first of all the essential service water system and the emergency power supply system, the essential service water system consists of piping, water intake structures, and water intake control building. The underground pipelines connect the pumps located in the water intake building to the main reactor building and diesel building while crossing the lower level in the turbine hall. There are also back-up systems (e.g., the fire water system) that can be used as ultimate heat sinks in case of severe accident and backup power supply systems, too. These should be also included in the scope of analysis.

(b) Containment function has to be ensured for limiting the radioactive releases.

(c) Structures and systems with limited radioactive inventory, for example, auxiliary building, should preserve certain level of structural integrity for limiting the site releases.

(d) Control rooms and the structures along the escape routes: integrity and habitability of the barrack of fire brigade and Protected Command Centre have to be analysed and ensured.

(e) The Laboratory and Service Building that is connected to the controlled area of the plant has to be checked, whether the life safety is ensured and the escape routes are safe. (f) Buildings that may collapse should not damage the essential service water system and emergency power lines or hinder the implementation of emergency measures.

(4) The fourth is definition of the criteria for assessing whether the SSCs identified above comply with the above requirements as well as the methods for structural analysis. Definition of assumptions applicable for material properties and load combinations are also included in this step of process. Examples are as follows.

(a) Permanent deformation of pipelines of the essential service water systems can be accepted assuming that the overall integrity and leaktightness are ensured.

(b) According to IAEA Safety Guide NS-G-1.10 [11], the following conditions can be accepted for the containment regarding structural integrity.

(i) Level II: local permanent deformations are possible. Structural integrity is ensured, though with margins smaller than those for design base.

(ii) Level III: significant permanent deformations are possible, and some local damage is also expected. Normally, this level is not considered in case of severe accidents.

For leak-tightness, the following levels could be considered.

(i) Level II: the leak rate may exceed the design value, but the leak-tightness can be adequately estimated and considered in the design.

(ii) Level III: leak-tightness cannot be ensured owing to large deformations of the containment structure. Structural integrity may still be ensured.

Considering the design of Paks NPP, large permanent deformations of the containment walls and floors are allowed when the deformations are within the strain limits allowable for the liner that ensures the necessary leak-tightness of the containment.

Relative displacement between containment and structures connected to the containment has to be assessed from the point of view of integrity of essential service water pipelines crossing these locations.

(c) In case of Laboratory and Service Building, near collapse conditions (according to EUROCODE 8 Part 3 or FEMA-356 2000) are allowed, while the evacuation is ensured via safe escape routes. A near collapse condition is also acceptable in case of auxiliary building.

(d) Specific attention has to be paid to the water intake structure whether the functioning of 
the pumps and free cross section for intake is ensured.

Best estimate models, mean values of loads and material properties can be used in the analysis of the liquefaction effects. In best estimate models, contribution to the resistance of nonstructural elements can be accounted for. The calculation can be linear or nonlinear static. In case of containment (main reactor building), coupled soil-structure model is applicable.

The structures within the scope of safety analysis are rather different. The main reactor building foundation is at the depth of $8.5 \mathrm{~m}$, below groundwater table, while the piping of essential service water system is located near surface in dry sand. The analysis methods selected for each structure within the scope have to fit to the specific design and soil conditions.

(5) The fifth is performing the analysis, conclusion on the plant response to liquefaction, and identification of the safety upgrading measures for ensuring the effective accident management and development of accident management guidance.

\section{Characterisation Liquefaction Hazard}

3.1. Geotechnical Investigations. Comprehensive geotechnical survey has been made for better understanding the site conditions and updating the database obtained prior to the construction of the plant. Altogether at the site $(500 \mathrm{~m} * 1000 \mathrm{~m}$ area), there are nearly 500 boreholes and other test points and more than 100 groundwater-monitoring wells. Site geotechnical survey includes mapping soil stratigraphy, in situ definition of soil properties, full scope laboratory testing of samples, cyclic triaxial and resonant column tests, Standard Penetration Tests (SPT), Cone Penetration Tests (CPT), Piezometric Cone Penetration Tests (CPTu), and Seismic Cone Penetration Tests (SCPT). Data are stored and presented in GeoDin database. The geotechnical investigations were performed in compliance with standards ISO 22475, ISO 22476, ISO/TS 17892, ASTM D3999-11, and ASTM 4015-07.

It has to be noted that the performance of geotechnical investigations at the plant site was rather difficult because of underground structures and lifelines. On the other hand, the soil conditions close to the buildings were disturbed due to foundation excavations. Therefore, a control area has been selected north to the plant where undisturbed soil conditions could be studied. Of course the soil conditions at the control area are not completely identical to those below critical plant structures. These differences have to be accounted for properly.

The classical method for determining liquefaction potential is based on SPT measurements, which had been the most widely used procedure. CPT, however, has approached the same level, and newly developed CPT based correlations now represent coequal or even better status with regard to accuracy and reliability. Compared to SPT, CPT offers advantages with regard to cost, efficiency, repeatability, and consistency. The accuracy of SPT measurements is operatordependent and their usefulness depends on the soil type: they give the most useful results in case of fine-grained sands, while in case of clays and gravelly soils they provided results, which may very poorly represent the true soil conditions. However, the most important aspect is the continuity of data over depth. SPT can only be performed at vertical spacing of about $75 \mathrm{~cm}$ or more, so it can completely miss thin (but potentially important) liquefiable strata. CPT, in contrast, is fully continuous and so "misses" nothing.

3.2. Analysis of the Liquefaction Potential. In practice, empirical methods based on in situ geotechnical tests are the most frequently used for liquefaction potential evaluation. For the Paks site, the preliminary calculations using well-known empirical correlations for liquefaction potential provided rather controversial results; see, for example, [12] and more recently [13].

In these calculations, thorough comparison has been made for selection of the most appropriate method for analysis. Nine of the newest and most commonly used cyclic stress based empirical correlations and two promising energyrelated methods were considered initially; see Table 3.

Shear wave velocity based and, especially, energy-related methods have seen little use in practice; there is not too much experience about their application. For this reason, our focus was narrowed to the traditionally used CPT and SPT based stress methods.

The final goal of our investigation was to obtain seismically induced settlement map for the area of critical buildings and underground structures. Since the vicinity of the reactor building was explored mainly by CPTs and also because of the described above advantages of the CPT test, mapping was carried out using the CPT based methods. Since most of the empirical methods for settlement calculations rely on SPT blow counts, at those locations where CPT and SPT were performed in close proximity to each other, comparison of the settlement values obtained by the SPT and CPT based methods had been performed. One of them (signed by B3), located near the reactor building, was chosen in this paper for illustrative purposes. Soil conditions accounted for in the calculations are shown in Figure 2. The groundwater level was assumed to be $8 \mathrm{~m}$ below the surface.

The SPT and CPT based liquefaction assessment methods calculate factor of safety against liquefaction, that is, the ratio of cyclic resistance (CRR) to seismic demand, namely, to the cyclic stress ratio (CSR).

There are two approaches for calculating the CSR: it can be determined with site response analysis and it can be approximated by simplified equations provided for each liquefaction evaluation method. Site response analysis has to be performed by nonlinear total stress method without taking into account pore pressure increase. In many cases, nonlinear behaviour is modelled by equivalent linear method, which takes into account the degradation of the shear modulus versus shear strain by an iterative procedure. Although the real nonlinear time history analysis can be regarded as more accurate, the applicability of equivalent linear method has been studied. Its reason is that the dynamic behaviour of 
TABLE 3: Liquefaction potential evaluation methods compared in the analysis.

\begin{tabular}{lcc}
\hline Method & Intensity measure & Empirical basis \\
\hline $\begin{array}{l}\text { Youd and Idriss (2001) [17] } \\
\text { Robertson and Wride (1998) [26] }\end{array}$ & & SPT \\
Andrus and Stokoe (2000) [28] & Peak ground \\
Cetin et al. (2004) [15] & $\begin{array}{c}\text { acceleration and } \\
\text { magnitude }\end{array}$ \\
Moss et al. (2006) [27] & & \\
Kayen et al. (2013) [29] & & \\
Idriss and Boulanger (2008, 2012, 2014) [20,30,31] & & SPT \\
Juang et al. (2006) [32] & & $V_{\text {s }}$ \\
\hline Kayen and Mitchell (1997) [33] & SPT, CPT \\
Kramer and Mitchell (2006) [34] & Arias intensity & CPT \\
\hline
\end{tabular}

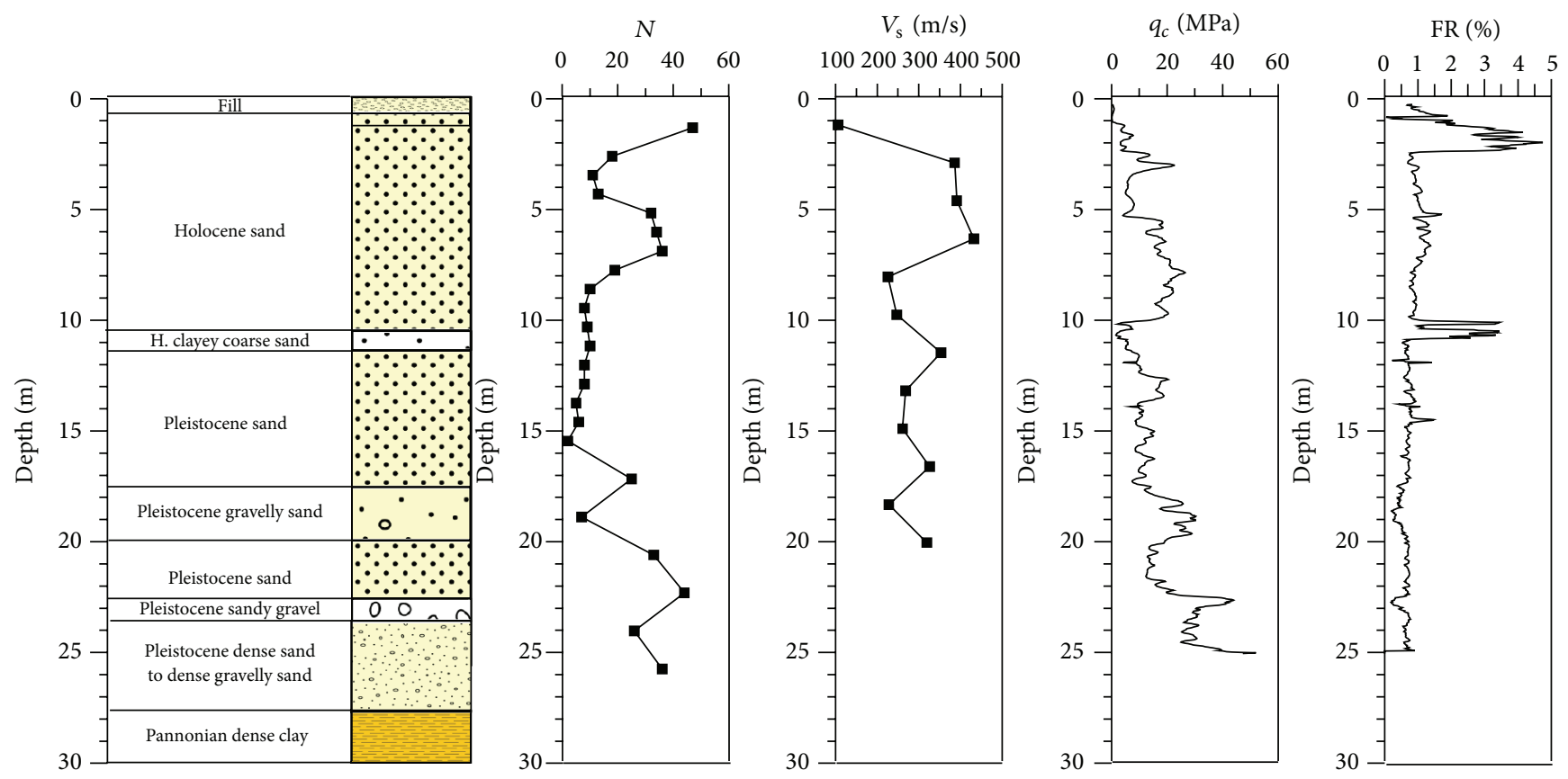

FIgURE 2: Soil profile, SPT blow counts $(N)$, shear wave velocities $\left(V_{s}\right)$, CPT penetration resistances $\left(q_{c}\right)$, and friction ratios (FR) measured at one of the studied points, signed by B3.

the building complex can be studied also using equivalent linear method because of the large complex model.

Peak ground acceleration (PGA or $a_{\max }$ ) was computed for the design basis earthquake with $10^{-4}$ /a annual frequency. Nonlinear computations have resulted in $a_{\max }=0.25 \mathrm{~g}$, while equivalent linear methods have given $0.29 \mathrm{~g}$ for the mean surface peak ground acceleration. From the point of view of liquefaction hazard, the moment magnitude of controlling earthquake has been determined to be equal to 6.0 using method of Marrone et al. [14]. In the simplified equations for CSR, the surface acceleration given by nonlinear method was applied.
The stress reduction factors obtained using the equivalent linear and nonlinear approaches are shown in Figure 3(a) in comparison with the results of simplified equations of Cetin [15, 16], Youd and Idriss [17], and Idriss [18]. This shows that difference between the different approaches can be significant, which can strongly influence both factor of safety against liquefaction and the resulting settlement. For this reason, it is highly recommended to use site response analysis for the evaluation of stress reduction with depth for high-risk facilities. From the simplified equations, the formula of Cetin [16] provided the best estimation of the actual behaviour of the soil column. It can be noted that some difference 


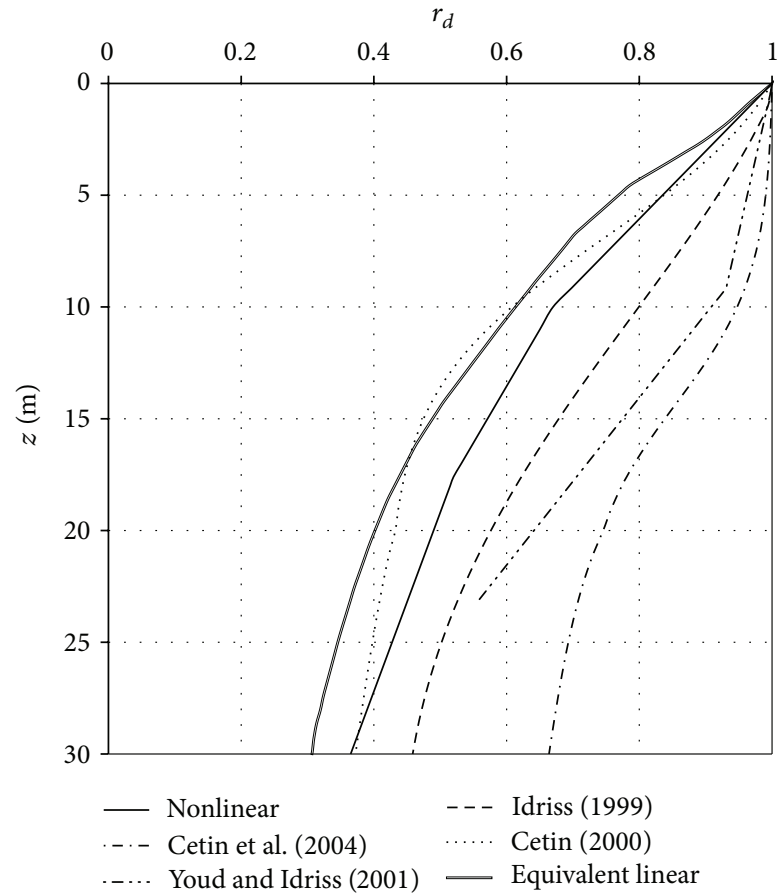

(a)

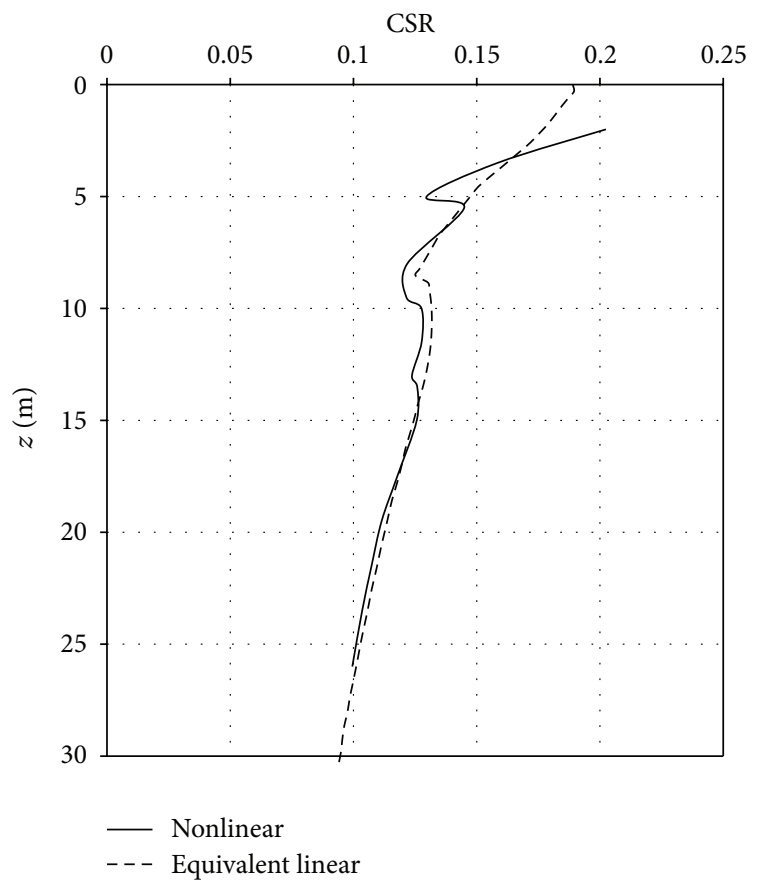

(b)

FIGURE 3: Stress reduction factors computed by different simplified equations, in addition to nonlinear and equivalent linear method (a) and cyclic stress ratio determined by nonlinear and equivalent linear method (b).

can be observed between the result of equivalent linear and nonlinear approach; stress reduction factor computed by equivalent linear method decreases faster. However, in their corresponding cyclic stress ratio (CSR) values, negligible difference can be observed in the depth of interest (Figure 3(b)), because difference in stress reduction factor and PGA compensate each other. Therefore, the CSR computed by equivalent linear method has been used hereinafter to be consistent with the selected method for the soil-structure interaction analysis.

The analysis of in situ test records and resistance against liquefaction show that subsoil conditions around the reactor buildings are slightly differing from those at the control site. Around the reactors from liquefaction-induced settlement point of view, the most vulnerable layer is located mostly between 10 and $16 \mathrm{~m}$ in depths, but in some locations settlement was predicted in $18-20 \mathrm{~m}$ depths also. This finding slightly differs from the earlier results of the authors [12], where the most susceptible layer for liquefaction was computed to be between 16 and $22 \mathrm{~m}$ in depths on the control site. This critical depth deserves attention, because of two main reasons.

(i) The depth of $15-20 \mathrm{~m}$ is around the limit for which simplified procedures have been verified and uncertainty in the results can be significant.

(ii) It should be mentioned that relatively large depth of the critical layers unfavourably influences pore pressure dissipation, but on the other hand the layers are underlain by gravelly deposit, which facilitate the dissipation of excess pore pressure.

Even at those locations where CPT and SPT tests were performed in a close proximity and it is reasonable to assume that they represent the same soil conditions, factors of safety based on the two tests are rather differing (Figure 4(a)). Moreover, significant variation can be observed in the factors of safety provided by methods using the same in situ index record. High uncertainty in the SPT based methods is mainly the result of difference in the methods' CRR-normalized blow-count correlations, which can be traced back to misinterpretation of few field cases during their development [19]. CRR-normalized CPT tip resistance correlations agree quite well with each other for relatively low seismic loading conditions, so uncertainty of the CPT based methods largely arises from the tip resistance normalization, especially from the fines content correction. Effect of two available fines content corrections on factor of safety is illustrated by an example in Figure 4(b).

After thorough consideration, the method of Boulanger and Idriss [20] was selected from the CPT based methods for mapping liquefaction potential of the reactor area. Our choice has fallen on this method because of the following reasons.

(i) Besides being deterministic, it also allows probabilistic approach of the problem, and probability of liquefaction occurrence can be incorporated into the performance-based framework of building safety evaluation. 


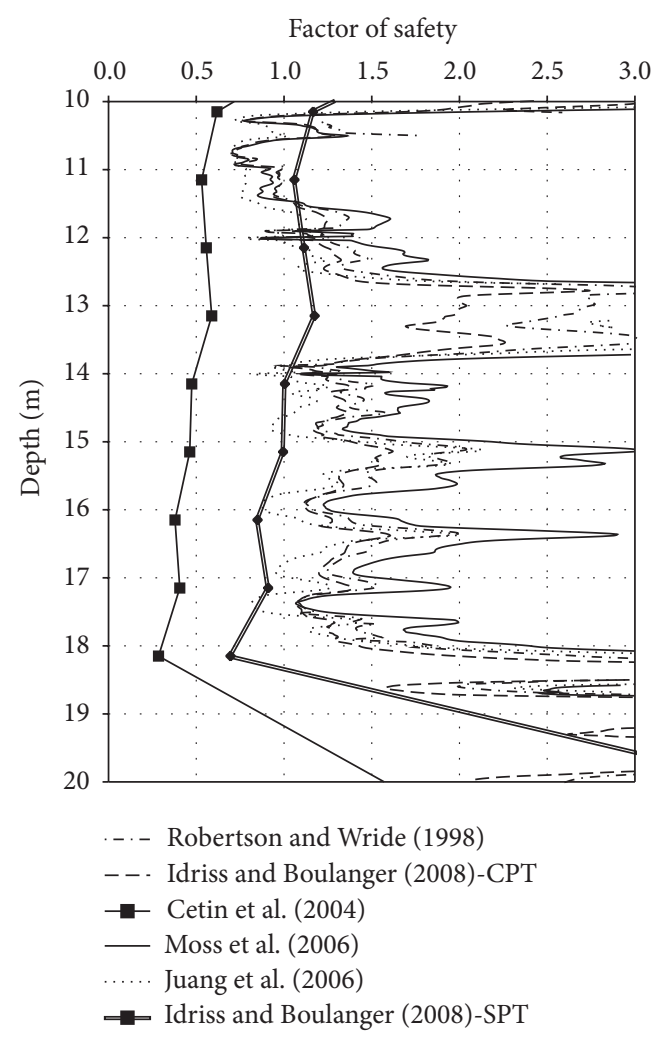

(a)

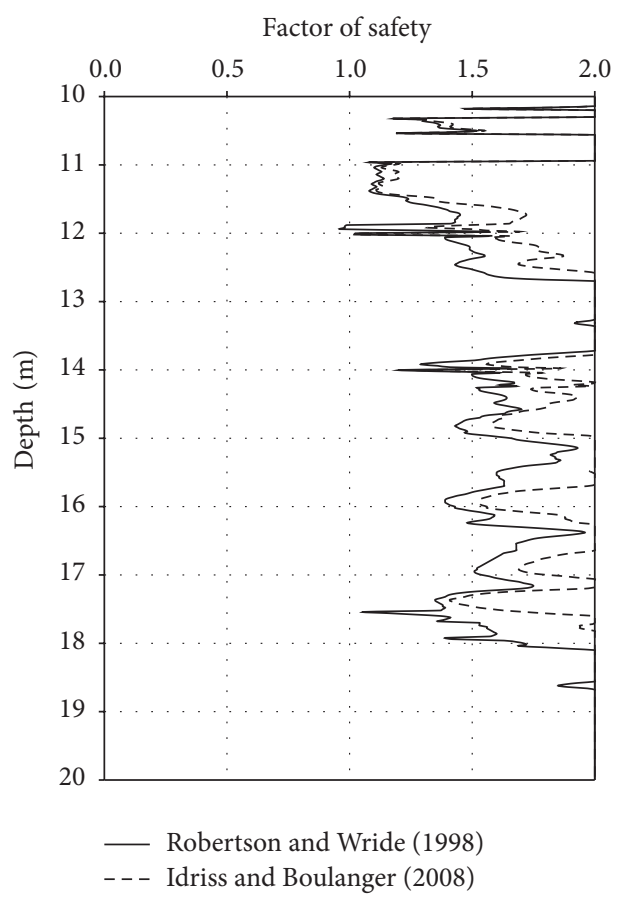

(b)

FIGURE 4: Factor of safeties against liquefaction computed by different SPT and CPT based methods (a) and by CPT based method of Idriss and Boulanger using different empirical correlations to determine fines content (b).

(ii) The authors have developed CPT and SPT based procedures too and the results given by their SPT based method are the closest to the results of CPT based methods.

(iii) The probabilistic method of Moss et al. was regressed from a liquefaction case history database, but for this reason its applicability in deeper depths than $12 \mathrm{~m}$ is uncertain. Boulanger and Idriss have used critical state soil mechanics to extend their formula in deeper depths, which is regarded as improvement in liquefaction potential evaluation [20].

(iv) The authors of the method have been continuously revising and updating their method with their latest results for approximately 10 years. They published revised corrections and updates in 2008, 2010, and 2012 and recently in 2014 including liquefaction case histories from the most recent earthquakes of 20102011 Canterbury earthquakes and 2011 Great Tohoku earthquake. Thus this method can be considered as the most up-to-date correlation.

(v) As the task was not a design problem but was the assessment of an existing building, at the selection of methods, we aspired to limit the conservatism involved in the calculation.
3.3. Settlement due to Liquefaction. The main goal of the evaluation is to determine the anticipated postliquefaction displacements. As most of the empirical settlement calculation methods are based on SPT blow-count numbers, mainly these methods had been used in earlier studies. Because many CPT tests were carried out around the main building complex of Paks NPP and CPT has many advantages over SPT, CPT based liquefaction potential and settlement evaluation method was used finally.

In the frame of preparatory studies for Paks NPP site, several methods for settlement computation have been compared: SPT based methods of Ishihara and Yoshimine [21], Tokimatsu and Seed [22], Wu and Seed [23], and Cetin et al. [24], as well as the CPT based method of Zhang et al. [25]. Most of these methods rely on factor of safety against liquefaction and/or normalized penetration resistance, so they have to be used in conjunction with liquefaction potential evaluation methods. The first two methods are compatible with the methods of Youd et al. and Idriss and Boulanger methods, while the $\mathrm{Wu}$ and Seed procedure can be used with the method of Cetin et al.

Cetin et al. [24] used a new approach to develop their correlation for empirical settlement analysis. Instead of using laboratory results, high-quality cyclically induced ground settlement case history formed the base of their method, which allowed probabilistic assessment of the database. Their 
procedure is based on CSR and SPT blow-counts normalized to energy, overburden pressure, and clean sand. The method proposes the use of a depth weighting factor, which takes into account the observation that deeper layers play less important role in the surface settlement. Their statistical assessment showed that the optimum value of this threshold depth is $18 \mathrm{~m}$. Because of these features, this method can be considered as most appropriate among the investigated ones.

From the CPT based settlement calculation methods, only one option, the procedure of Zhang et al. [25], was available for the analysis. This method computes the volumetric strain from factor of safety against liquefaction and CPT tip resistance normalized to clean sand. The authors proposed the use of Robertson and Wride [26] method to compute the factor of safety, which was at that time the state-of-the-art CPT method.

According to Cetin et al. [24], we have limited the depth of settlement calculations but the threshold depth was taken more conservatively to $20 \mathrm{~m}$. For $B 3$ point, the procedure of Zhang in conjunction with the methods of Robertson and Wride [26], Moss et al. [27], and Boulanger and Idriss [20] resulted in the following settlements: $0.8 \mathrm{~cm}, 9.2 \mathrm{~cm}$, and $1.6 \mathrm{~cm}$, respectively. We used the method of Boulanger and Idriss for mapping because of the reasons presented above in Section 3.2.

Comparison of these values with the results of SPT based calculations showed that in general all of the SPT based settlements were significantly larger than the CPT based values. The largest settlement was predicted by Ishihara and Yoshimine as well as by the Tokimatsu and Seed methods, while Cetin et al. gave the lowest values. After thorough revision of the results, methods, and tests, it was noted that probably some kind of error distorts the SPT records in a few test points. In those places where all CPT, SPT, and $V_{\mathrm{s}}$ were available, CPT and $V_{s}$ records showed very similar sequence of stiffer and softer layers, but SPT blow-count numbers have contradicted to that stratigraphy.

The extent of the geotechnical survey allowed the assessment of lateral variability of soil conditions. Mapping of seismically induced settlement was based on altogether 29 CPT records around the reactor buildings and the values were varying between $0.1 \mathrm{~cm}$ and $5.1 \mathrm{~cm}$. However, this maximum value is quite outlier, because in most of the test points less than $1 \mathrm{~cm}$ settlement was predicted, and the settlement exceeded $2 \mathrm{~cm}$ in only four test points.

The free surface settlement was computed using effective stress method [19] to the average soil profile. It gave $0.67 \mathrm{~cm}$ as average settlement, which is consistent with the results given by the combination of Zhang et al. and Boulanger and Idriss methods.

\section{Conclusion}

In the paper, an important application of liquefaction assessment is discussed: beyond design base analysis of liquefaction consequences for nuclear power plants. Detailed framework for performing the safety analysis for liquefaction consequences is outlined in the paper. Deterministic safety analysis of nuclear power plant for earthquake-induced liquefaction is a complex task that requires adequate modelling of the plant response and characterization of the hazard and engineering demand parameter of the liquefaction, as well as the assessment of the integrity and function of plants systems, structures, and components. Preparatory analyses and considerations show that the settlement could be the dominating engineering demand parameter for the case of Paks NPP site. Adequacy of safety analyses and conclusiveness of the results is mainly limited by the epistemic uncertainty of the methods of hazard definition and the engineering parameters characterising the consequences of liquefaction and controlling the plant response. In the paper, detailed comparison of available methodologies has been made for adequate selection of methods for calculation of the settlement.

\section{Conflict of Interests}

The authors declare that there is no conflict of interests regarding the publication of this paper.

\section{References}

[1] L. Tóth, E. Győri, and T. J. Katona, "Current Hungarian practice of seismic hazard assessment," in Recent Findings and Developments in Probabilistic Seismic Hazards Analysis (PSHA) Methodologies and Applications, Proceedings of the OECD NEA Workshop (NEA/CSNI/R(2009)1), 2009.

[2] T. J. Katona, "Seismic safety analysis and upgrading of operating nuclear power plants," in Nuclear Power-Practical Aspects, W. Ahmed, Ed., chapter 4, pp. 77-124, InTech, New York, NY, USA, 2012.

[3] O. Arup and Partner, "Seismic hazard reevaluation tasks 1, 2, 3, 4, and 7," Final Report Project no.: 4.2.1, PHARE Regional Programme Nuclear Safety, 1995.

[4] HAEA, National Report of Hungary on the Targeted Safety Re-Assessment of Paks Nuclear Power Plant, HAEA, Budapest, Hungary, 2011.

[5] IAEA, "Severe accident management programmes for nuclear power plants," Safety Guide NS-G-2.15, International Atomic Energy Agency, Vienna, Austria, 2008.

[6] http://www-ns.iaea.org/tech-areas/seismic-safety/default.asp? $s=2 \& l=65$.

[7] S. Dashti, J. D. Bray, J. M. Pestana, M. Riemer, and D. Wilson, "Mechanisms of seismically induced settlement of buildings with shallow foundations on liquefiable soil," Journal of Geotechnical and Geoenvironmental Engineering, vol. 136, no. 1, pp. 151164, 2010.

[8] C. A. Cornell and H. Krawinkler, "Progress and challenges in seismic performance assessment," PEER News, pp. 1-3, 2000.

[9] G. G. Deierlein, H. Krawinkler, and C. A. Cornell, "A framework for performance-based earthquake engineering," in Proceedings of the Pacific Conference on Earthquake Engineering, Christchurch, New Zealand, February 2003.

[10] F. Zareian and F. Krawinkler, "Simplified performance based earthquake engineering," Tech. Rep. 169, The John A. Blume Earthquake Engineering Center, Stanford University, Stanford, Calif, USA, 2009.

[11] IAEA, Design of Reactor Containment Systems for Nuclear Power Plants, International Atomic Energy Agency, Vienna, Austria, 2004. 
[12] E. Győri, L. Tóth, Z. Gráczer, and T. Katona, "Liquefaction and post-liquefaction settlement assessment-a probabilistic approach," Acta Geodaetica et Geophysica Hungarica, vol. 46, no. 3, pp. 347-369, 2011.

[13] E. Győri, T. J. Katona, Z. Bán, and L. Tóth, "Methods and uncertainties in liquefaction hazard assessment for nuclear power plants," in Proceedings of the 2nd European Conference on Earthquake Engineering and Seismology, Istanbul, Turkey, August 2014.

[14] J. Marrone, F. Ostadan, R. Youngs, and J. Litehiser, "Probabilistic liquefaction hazard evaluation: method and application," in Proceedings of the 17th International Conference on Structural Mechanics in Reactor Technology (SMiRT-17 '03), vol. 17 22, Prague, Czech Republic, August 2003.

[15] K. O. Cetin, R. B. Seed, A. der Kiureghian et al., "Standard penetration test-based probabilistic and deterministic assessment of seismic soil liquefaction potential," Journal of Geotechnical and Geoenvironmental Engineering, vol. 130, no. 12, pp. 1314-1340, 2004.

[16] K. O. Cetin, Reliability-based assessment of of seismic soil liquefaction initiation hazard [Ph.D. dissertation], University of California, Berkeley, Calif, USA, 2000.

[17] T. L. Youd and I. M. Idriss, "Liquefaction resistance of soils: Summary report from the 1996 NCEER and 1998 NCEER/NSF workshops on evaluation of liquefaction resistance of soils," Journal of Geotechnical and Geoenvironmental Engineering, vol. 127, no. 4, pp. 297-313, 2001.

[18] I. M. Idriss, "An update of the Seed-Idriss simplified procedure for evaluating liquefaction potential," Proceedings: TRB Workshop on New Approaches to Liquefaction Analysis FHWARD-99-165, Federal Highway Administration, Washington, DC, USA, 1999.

[19] I. M. Idriss and R. W. Boulanger, "SPT-based liquefaction triggering procedures," Tech. Rep. UCD/CGM-10/02, University of California, Davis, Calif, USA, 2010.

[20] R. W. Boulanger and I. M. Idriss, "CPT and SPT based liquefaction triggering procedures," Tech. Rep. UCD/CGM-14/01, University of California, Davis, Calif, USA, 2014.

[21] K. Ishihara and M. Yoshimine, "Evaluation of settlements in sand deposits following liquefaction during earthquakes," Soils and Foundations, vol. 32, no. 1, pp. 178-188, 1992.

[22] K. Tokimatsu and B. H. Seed, "Evaluation of settlements in sands due to earthquake shaking," Journal of Geotechnical Engineering, vol. 113, no. 8, pp. 861-878, 1987.

[23] J. Wu and R. B. Seed, "Estimating of liquefaction-induced ground settlement case studies," in Proceedings of the 5th International Conference on Case Histories in Geotechnical Engineering, Paper 3.09, New York, NY, USA, April 2004.

[24] K. O. Cetin, H. T. Bilge, J. Wu, A. M. Kammerer, and R. B. Seed, "Probabilistic model for the assessment of cyclically induced reconsolidation (Volumetric) settlements," Journal of Geotechnical and Geoenvironmental Engineering, vol. 135, no. 3, pp. 387-398, 2009.

[25] G. Zhang, P. K. Robertson, and R. W. I. Brachman, "Estimating liquefaction-induced ground settlements from CPT for level ground," Canadian Geotechnical Journal, vol. 39, no. 5, pp. 11681180, 2002.

[26] P. K. Robertson and C. E. Wride, "Evaluating cyclic liquefaction potential using the cone penetration test," Canadian Geotechnical Journal, vol. 35, no. 3, pp. 442-459, 1998.

[27] R. E. S. Moss, R. B. Seed, R. E. Kayen, J. P. Stewart, A. Der Kiureghian, and K. O. Cetin, "CPT-based probabilistic and deterministic assessment of in situ seismic soil liquefaction potential," Journal of Geotechnical and Geoenvironmental Engineering, vol. 132, no. 8, pp. 1032-1051, 2006.

[28] R. D. Andrus and K. H. Stokoe II, "Liquefaction resistance of soils from shear-wave velocity," Journal of Geotechnical and Geoenvironmental Engineering, vol. 126, no. 11, pp. 1015-1025, 2000.

[29] R. Kayen, R. E. S. Moss, E. M. Thompson et al., "Shear-Wave velocity-based probabilistic and deterministic assessment of seismic soil liquefaction potential," Journal of Geotechnical and Geoenvironmental Engineering, vol. 139, no. 3, pp. 407-419, 2013.

[30] I. M. Idriss and R. W. Boulanger, "Soil liquefaction during earthquakes," in Monograph MNO-12, p. 261, Earthquake Engineering Research Institute, Oakland, Calif, USA, 2008.

[31] I. M. Idriss and R. W. Boulanger, "Examination of SPT-based liquefaction triggering correlations," Earthquake Spectra, vol. 28, no. 3, pp. 989-1018, 2012.

[32] C. H. Juang, S. Y. Fang, and E. H. Khor, "First-order reliability method for probabilistic liquefaction triggering analysis using CPT," Journal of Geotechnical and Geoenvironmental Engineering, vol. 132, no. 3, pp. 337-350, 2006.

[33] R. E. Kayen and J. K. Mitchell, "Assessment of liquefaction potential during earthquakes by arias intensity," Journal of Geotechnical Engineering, vol. 123, no. 12, pp. 1162-1174, 1997.

[34] S. L. Kramer and R. A. Mitchell, "Ground motion intensity measures for liquefaction hazard evaluation," Earthquake Spectra, vol. 22, no. 2, pp. 413-438, 2006. 


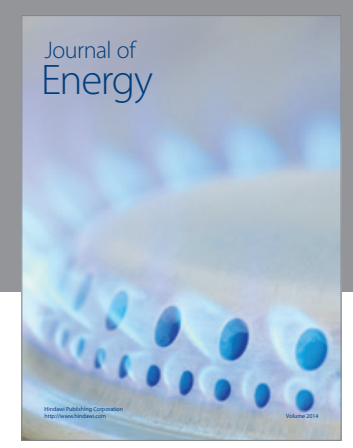

Journal of

Industrial Engineering
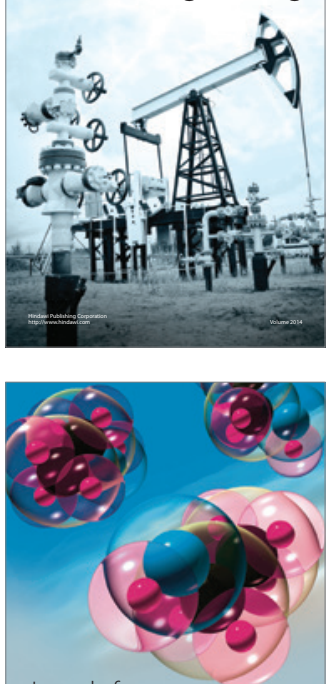

Fuels
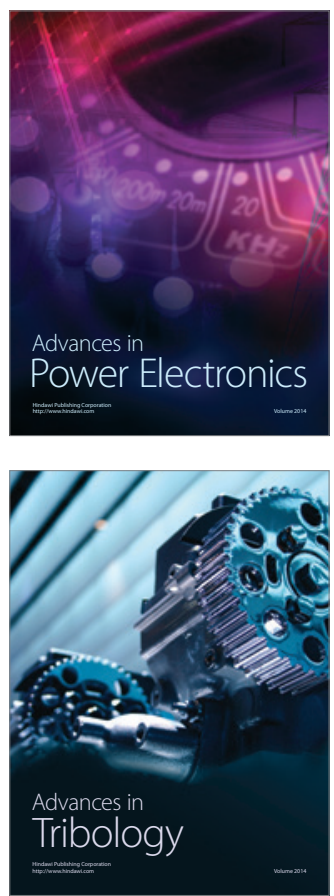

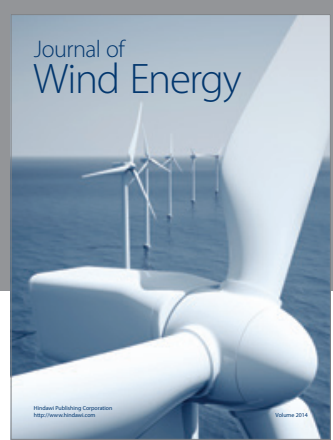

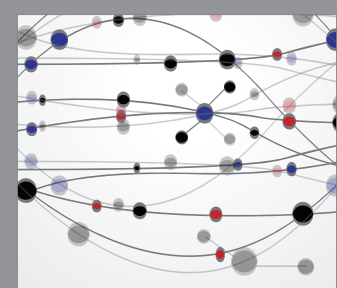

The Scientific World Journal

Submit your manuscripts at http://www.hindawi.com

Journal of

Structures
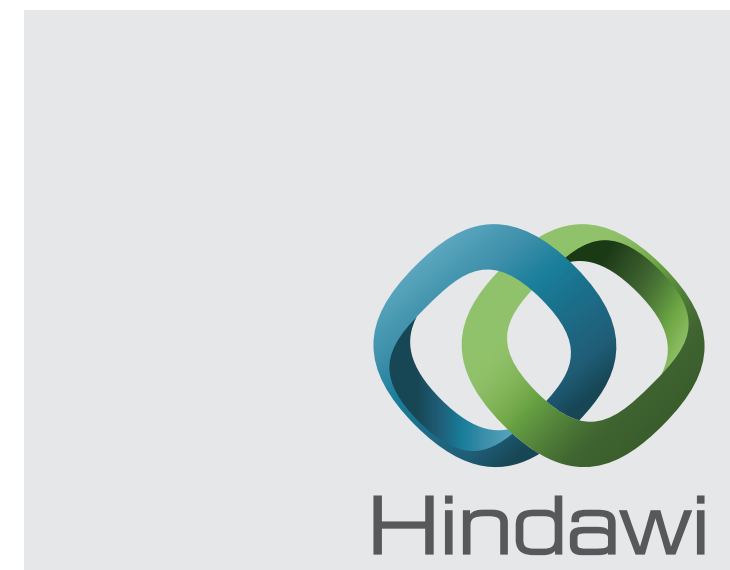

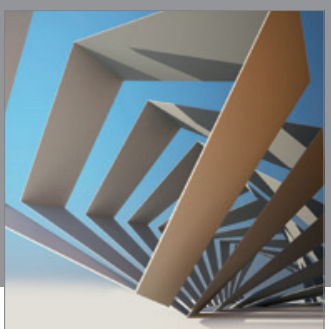

Rotating

Machinery
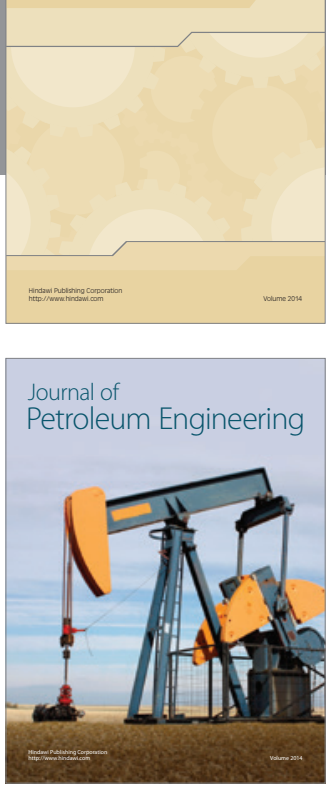

Journal of

Solar Energy
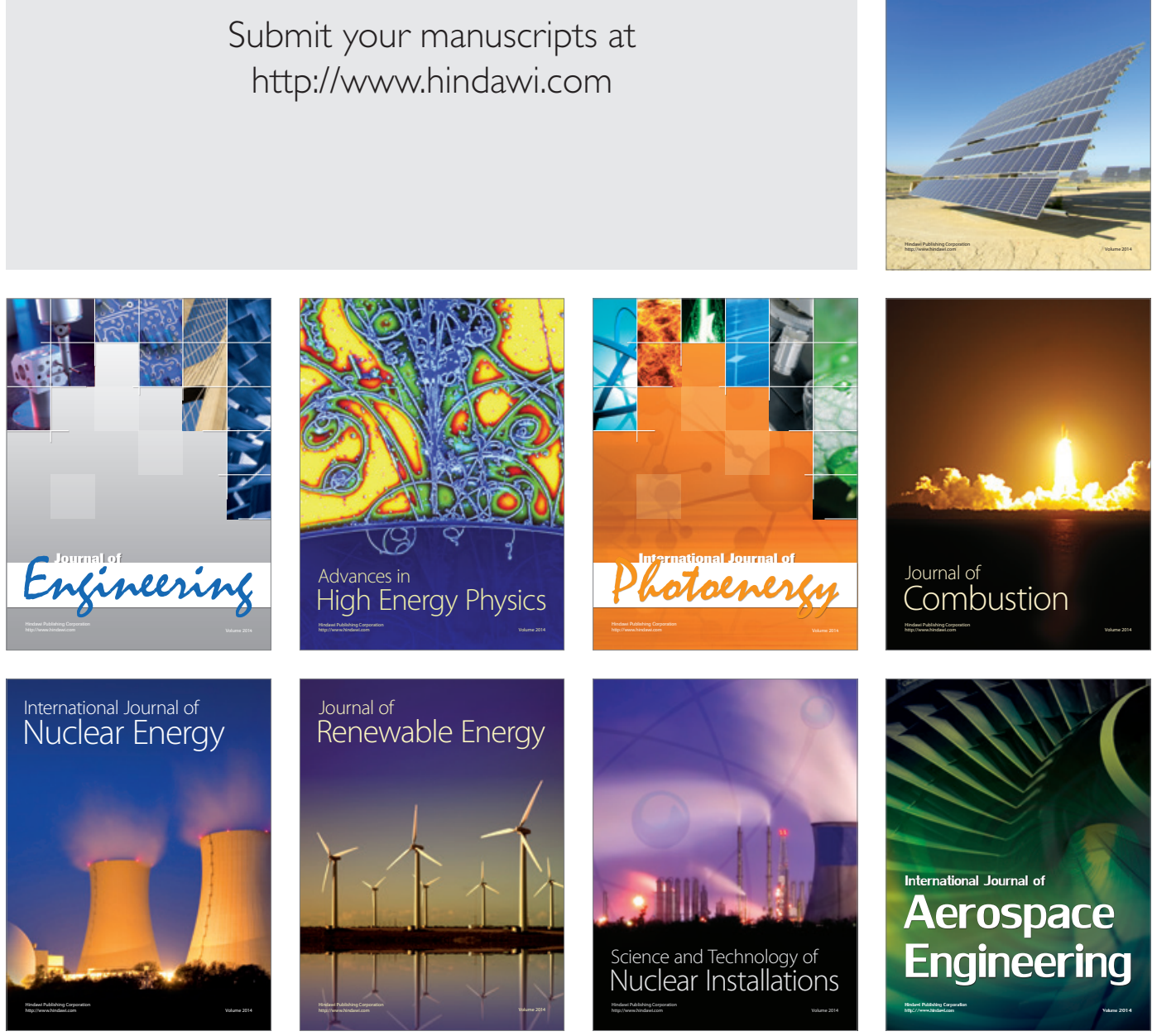